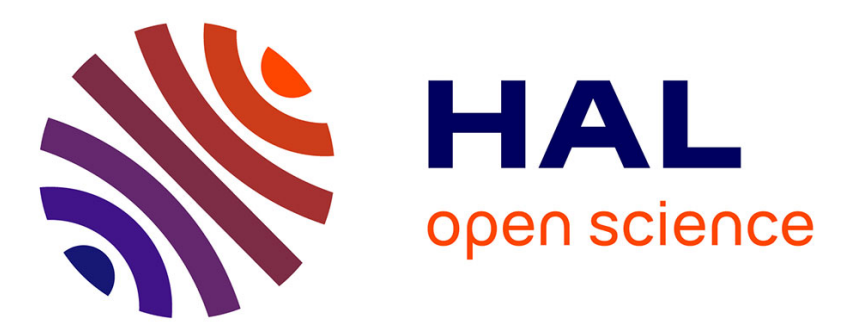

\title{
Principle, characterization and control of a new hybrid thermo-piezoelectric microactuator.
}

\author{
Micky Rakotondrabe, Ioan Alexandru Ivan
}

\section{To cite this version:}

Micky Rakotondrabe, Ioan Alexandru Ivan. Principle, characterization and control of a new hybrid thermo-piezoelectric microactuator.. IEEE International Conference on Robotics and Automation, ICRA'10., May 2010, Anchorage - Alaska, United States. pp.1580-1585. hal-00504024

\section{HAL Id: hal-00504024 \\ https://hal.science/hal-00504024}

Submitted on 19 Jul 2010

HAL is a multi-disciplinary open access archive for the deposit and dissemination of scientific research documents, whether they are published or not. The documents may come from teaching and research institutions in France or abroad, or from public or private research centers.
L'archive ouverte pluridisciplinaire HAL, est destinée au dépôt et à la diffusion de documents scientifiques de niveau recherche, publiés ou non, émanant des établissements d'enseignement et de recherche français ou étrangers, des laboratoires publics ou privés. 


\title{
Principle, characterization and control of a new hybrid thermo-piezoelectric microactuator
}

\author{
Micky Rakotondrabe, Member, IEEE and Ioan Alexandru Ivan, Member, IEEE
}

\begin{abstract}
This paper presents a new actuator based on a unimorph piezocantilever and on the thermal bimorph principle, called hybrid thermopiezoelectric actuator. The main advantage of the proposed actuator is the high range of positioning from the thermal actuation and the high resolution and bandwidth from the piezoelectric one. A characterization and linear modeling are proposed. Finally, we propose an adapted control law to manage the two possible actuation types.
\end{abstract}

\section{INTRODUCTION}

In micromanipulation and microassembly, the actuators (called microactuators) are designed differently from classical actuators in order to fulfil the required performances. These microactuators should perform high resolution and high accuracy (often submicrometric), sometimes a quick settling time, and finally a high range of positioning. So, instead of using hinges, smart/active materials (piezoelectric, thermal deformation based, shape memory alloy, electrostatic, etc.) are used to design microactuators.

One of the well appreciated smart materials for microactuators is the piezoelectric material. For instance, it has successfully been used to develop Atomic Force Microscopes (AFM) [1], stepper microactuators and microrobots such as stick-slip ones [2][3][4], linear microactuators such as piezocantilevers and microgrippers [5][6][7], and ultrasonic (with progressive wave) micromotors [8]. In fact, piezoelectric microactuators offer nanometric resolution, a low settling time (in the order of some milliseconds if controlled [9]) and a high force density. Nevertheless, the positioning range of piezoelectric microactuators is very limited. Two possibilities exist for the range amplification. The first consists in applying higher input voltages but this method can depolarize or destroy the microactuators. The second one consists in optimizing the microactuator design [10] but this can lead to complex structures that are often difficult to fabricate.

Contrarily to piezoelectric microactuators, thermal ones offer a high range of displacement. They were successfully used to design microgrippers and micropositioning devices [11][12][13]. The well known principle

FEMTO-st Institute,

UMR CNRS-6174 / UFC / ENSMM / UTBM

Automatic Control and Micro-Mechatronic Systems department (AS2M department)

25000 Besançon - France

\{mrakoton, alex.ivan\}@femto-st.fr of the thermal microactuator is the thermal bimorph. It is a cantilever based on two layers of different thermal expansion coefficients. When subjected to a temperature variation, the two layers differently expand (or contract) and then resulting in a bending of the cantilever. Despite the slow response time of thermal microactuators, they are well adapted to micromanipulation and microassembly tasks.

In this paper, we propose a new microactuator that combines the thermal bimorph principle and the piezocantilever microactuator. In fact, temperature has been considered as external disturbance to be rejected for piezoelectric actuators [14], while in this paper, we will show that it can be used as a benefit. The proposed microactuator, called hybrid thermo-piezoelectric, will benefit the high range of displacement from the thermal bimorph and the high resolution from the piezocantilever. Therefore, it can be used to do both large displacement and fine positioning, which are required in micromanipulation and microassembly. After characterizing and modeling the hybrid microactuator, we propose a simple control law that well manages these two positioning modes.

The paper is organized as follows. We present the principle and the developped microactuator in sectionII. Section-III is dedicated to its characterization and modeling. Finally, we introduce the controller design and closed-loop experimental results.

\section{Presentation of the hybrid microactuator}

\section{A. Principle}

Consider a unimorph piezocantilever which is made up of a piezoelectric layer and a passive layer (Fig. 1a). When submitted to an electrical field, the piezolayer expands (or contracts), resulting a global bending of the cantilever (Fig. 1-b). The unimorph piezocantilevers could also be employed as thermal bimorphs. When subjected to a temperature variation, the two layers expand (or contract) with different amounts resulting a bending of the cantilever (Fig. 1-c).

The two previous (piezoelectric and thermal bimorph) principles are used to design a hybrid microactuator. If the electrical excitation is easy to manage, the thermal one is more delicate. Indeed, there are many contrains on the thermal signal generation:

- thermal signal is not easy to precisely provide,

- overshoots on temperature variations may lead to the destruction of the microactuator, 
(a)
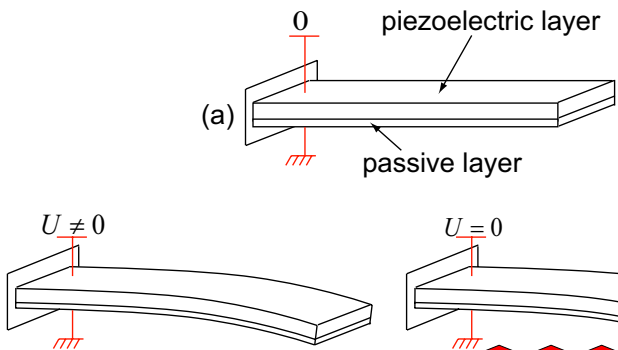

(b)

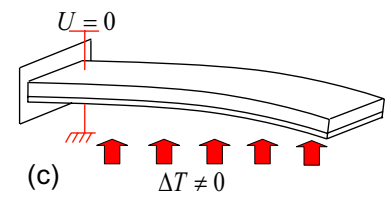

Fig. 1. Principle of a unimorph piezocantilever: (a) at rest, (b) piezoelectrically excited, (c) thermally

- and finally, to obtain two directions of deflection (positive and negative), both heating and cooling in $\Delta T$ should be used.

To account these constrains, we propose to use a small Peltier module, also called ThermoElectric Cooler (TEC) device. Its main advantages refer to the use of electrical (current) input signal, making standard the control, and the possibility of both cooling and heating easily. For instance, TEC-device has been successfully used to the design of special microactuators for liquid medias [15]. In our case, one side of the TEC-device is used to embed the unimorph piezocantilever while the other side is placed on a cooling block (Fig. 2). This cooling block is used to efficiently transfer the heat from the TEC-device and piezocantilever during the heating/cooling.

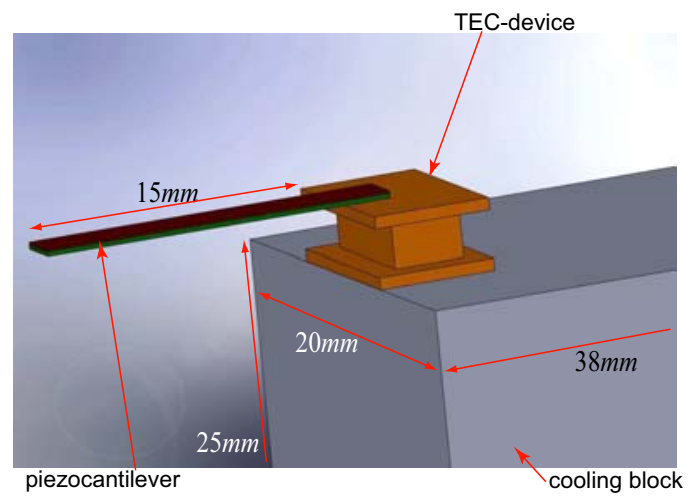

Fig. 2. Scheme of the hybrid microactuator.

The piezocantilever is based on soft PZT-layer (Lead Zirconate Titanate ceramic PIC151) and a copper-layer. Aluminium is used for the cooling block. Finally, we use a standard TEC-module (PE-011-05-15 from Supercool [16]). The sizes of the hybrid microactuator are summarized in Table $\mathrm{I}$.

\section{B. Experimental setup}

The setup, pictured in Fig. 3, is composed of:

- the hybrid thermo-piezoelectric microactuator (piezocantilever, TEC-device and cooling block),
TABLE I

Geometrical characteristics.

\begin{tabular}{|l||l||l|}
\hline \hline Symbol & title & value \\
\hline$h_{s}$ & height of the cooling block & $25 \mathrm{~mm}$ \\
\hline$L_{s}$ & length of the cooling block & $38 \mathrm{~mm}$ \\
\hline$w_{s}$ & width of the cooling block & $20 \mathrm{~mm}$ \\
\hline$S_{p}$ & area of the TEC-device & $8 \times 5 \mathrm{~mm}^{2}$ \\
\hline$L$ & $\begin{array}{l}\text { active length of the piezocan- } \\
\text { tilever }\end{array}$ & $15 \mathrm{~mm}$ \\
\hline$w$ & width of the piezocantilever & $2 \mathrm{~mm}$ \\
\hline$e_{p z t}$ & thickness of the PZT-layer & $0.2 \mathrm{~mm}$ \\
\hline$e_{c o p}$ & thickness of the copper-layer & $0.2 \mathrm{~mm}$ \\
\hline$e$ & total thickness & $=e_{p z t}+e_{c o p}$ \\
\hline \hline
\end{tabular}

- a computer and dSPACE-board for control and data acquisition. Matlab-Simulink ${ }^{\mathrm{TM}}$ software is used to manage the signals and implement the controllers,

- a HV (high voltage) amplifier for the piezocantilever,

- an electrical current amplifier for the TEC-device,

- a Keyence optical sensor (up to $10 \mathrm{~nm}$ resolution) to measure the piezocantilever's deflection,

- and a miniature NTC thermistor with opposite signal conditioning circuit which measures the temperature of the piezocantilever.

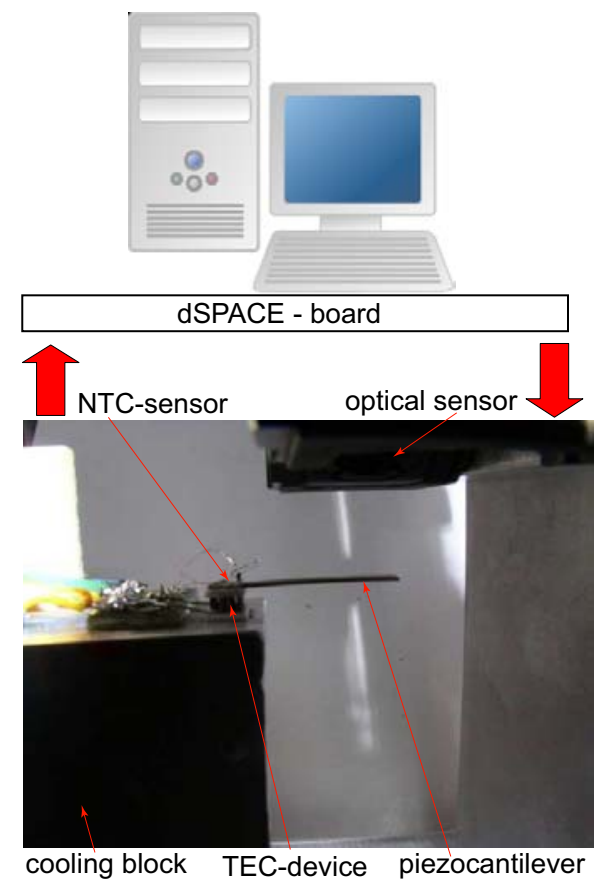

Fig. 3. The experimental setup.

\section{Characterization AND MODEling}

In this section, we characterize and model the whole hybrid microactuator. The systemic scheme of the microactuator is shown in Fig. 4. Two inputs are considered: the TEC current $i$ which causes a temperature change $\Delta T=T-T_{a}$, and the voltage $U$. Ambient temperature 
$T_{a}$ is considered to be constant and, without loss of meaning, we shall use $T$ instead of $\Delta T$ for the sequel.

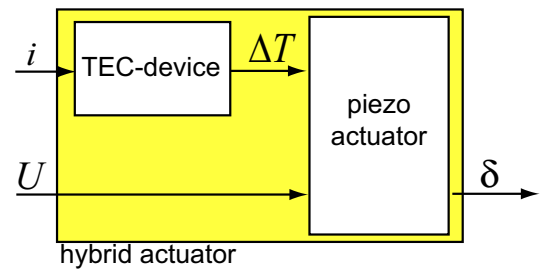

Fig. 4. Systemic scheme of the hybrid microactuator.

Smits and Choi [17] shows that the static relation between the output deflection $\delta$ of a unimorph piezocantilever and its two inputs $U$ and $T$ is affine:

$$
\delta=d_{p} U+f_{T \delta} T
$$

where $d_{p}$ is a piezoelectric coefficient and $f_{T \delta}$ is a thermomechanical coefficient. The latter especially depends on the thermal coefficients of the two layers.

On the other hand, the relation between the temperature $T$ provided by the TEC-device and the current $i$ is nonlinear [18]. But, assuming a small variation of $i$, a linear approximation is sufficient: $T=f_{i T} i$, with $f_{i T}$ a linearization coefficient of the TEC-device. We finally have:

$$
\delta=d_{p} U+f_{p} i
$$

where $f_{p}=f_{T \delta} f_{i T}$.

The previous equation is for the static mode. In order to account the dynamic behavior, we will generalize the formulation such as the dynamic part $D_{p}(s)$ of the piezoelectric effect is different from $D_{T}(s)$ of the thermomechanical effect. $s$ denotes the Laplace variable. So:

$$
\delta=d_{p} D_{p}(s) U+f_{p} D_{T}(s) i
$$

with $D_{p}(0)=1$ and $D_{T}(0)=1$ for normalization. In the sequel, we will characterize and identify the dynamic model expressed by (equ 3).

\section{A. Thermomechanical part}

First, we analyze the thermomechanical part $\delta=$ $f_{p} D_{T}(s) i$. The first experiment consists in applying a step input of $i=0.1 A$ to the hybrid microactuator. From the step response, the static gain $f_{p}$ and the normalized dynamic $D_{T}(s)$ are identified. A first order model is sufficient. We have:

$$
\frac{\delta(s)}{i(s)}=f_{p} D_{T}(s)=\frac{1200}{9.933 s+1}
$$

inside which $f_{p}=1200[\mu \mathrm{m} / A]$.

Afterwards, different values of step inputs $(i=0.05 \mathrm{~A}$ and $i=0.025 A$ ) are applied to the identified model and to the real system. The comparison, pictured in
Fig. 5, shows that the identified model well characterizes the behavior of the thermomechanical part, except the static gain obtained for $i=0.05 \mathrm{~A}$. In fact, the static part is slightly nonlinear due to the characteristic of the TEC-device. However, for the purpose of controller design, we admit that the proposed linear approximation is sufficient (see Fig. 6, dashed line for the simulation of $\delta=f_{p} i$, solid line for the experimental result).

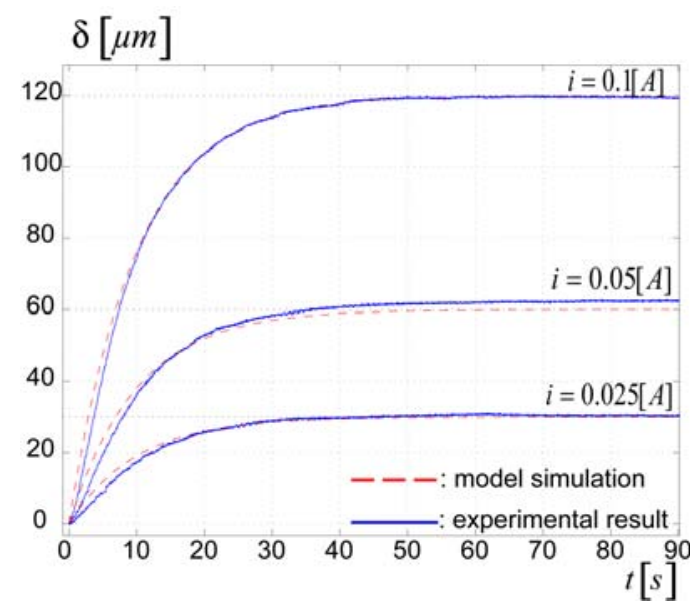

Fig. 5. Step response of the thermomechanical part.

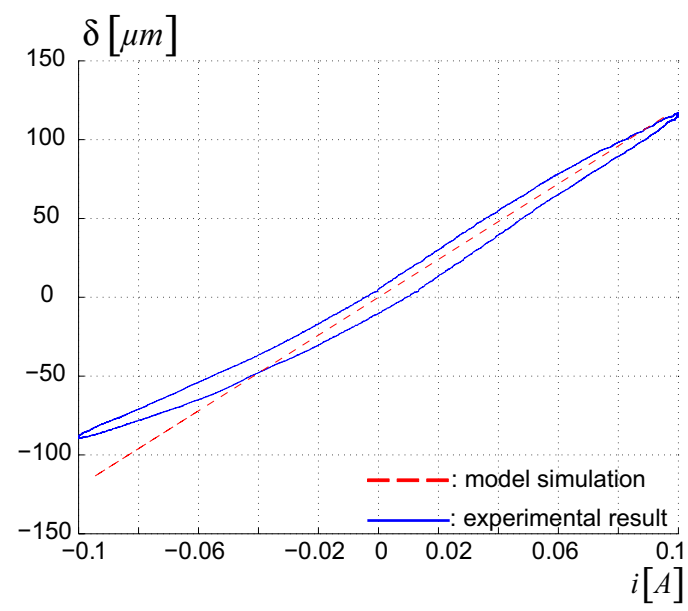

Fig. 6. Static characteristic of the thermomechanical part.

\section{B. Piezoelectric part}

We now characterize the piezoelectric part $\delta=$ $d_{p} D_{p}(s) i$. A step input voltage $U=40 \mathrm{~V}$ is first applied. From the experimental step response, the model $d_{p} D_{p}(s)$ is identified using an ARMAX method. Fig. 7 shows the comparison of the experimental result and the model simulation. We have:

$$
\frac{\delta(s)}{U(s)}=d_{p} D_{p}(s)=\frac{-75\left(s+1.2 \times 10^{4}\right)(s-9155)}{(s+2327)\left(s^{2}+40.47 s+1.9 \times 10^{7}\right)}
$$




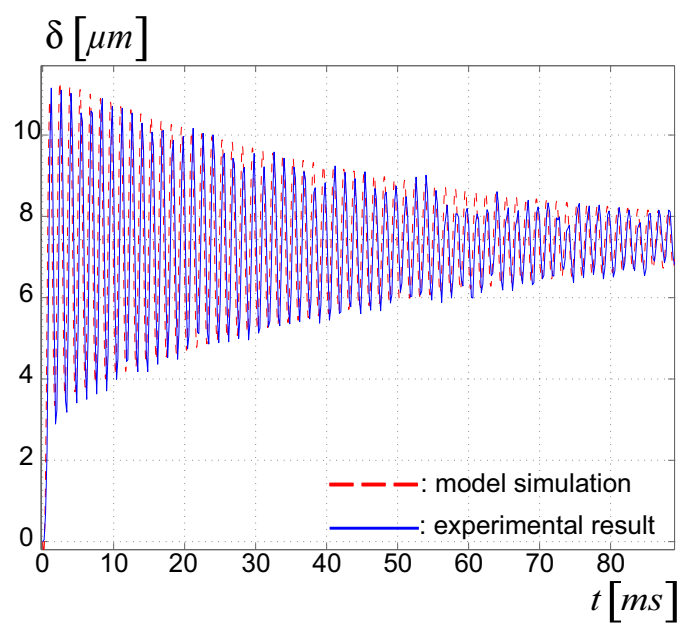

Fig. 7. Step response of the piezoelectric part $(U=40[V])$.

where $d_{p}=0.186(\mu m / V]$

Afterwards, a static analysis is performed. For that, a sine input $U$ is applied and the output $\delta$ is captured. The experimental result shows that the static behavior of the piezoelectric part is hysteretic (see Fig. 8, solid line for the experimental result, dashed line for the linear model $\left.\delta=d_{p} i\right)$. Hysteresis behavior is a well known nonlinear characteristic of piezoelectric ceramic materials. If the amplitude of the hysteresis is not large, a linear model is generally sufficient for a closed-loop control [19].

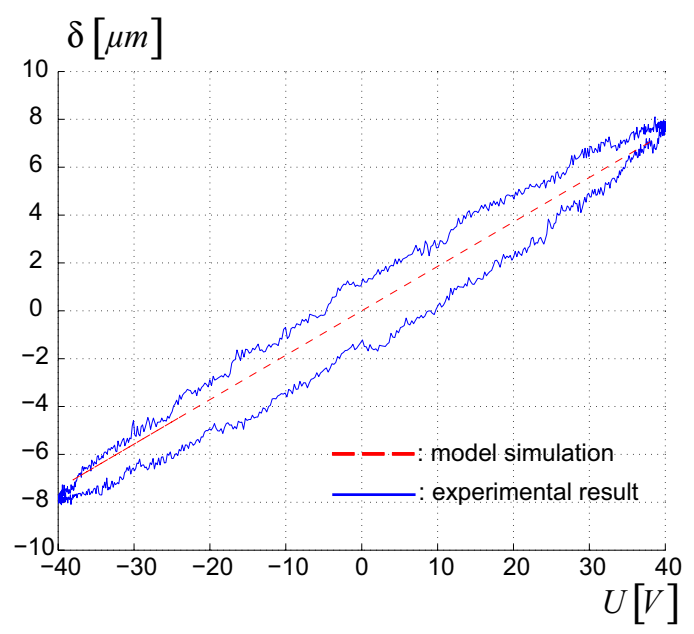

Fig. 8. Static characteristic of the piezoelectric part.

To sum up, the behavior of the hybrid microactuator is affected by some nonlinearities but we propose to use the linear approximation for easiness of controller design.

\section{Closed-LOop CONTROL}

In this section, we design a controller for the hybrid microactuator. The aim is to improve its performances in order to adapt them to the requirements of micromanipulation/microassembly tasks. For instance, the positioning or assembly of a micro-object takes two steps:
- first, a coarse positioning is performed by the hybrid microactuator. It consists in pushing or positioning the micro-object at a long distance without a special accuracy. The thermomechanical part of the hybrid microactuator can be used for that;

- afterwards, the fine positioning is performed thanks to the high resolution of the microactuator's piezoelectric part. Furthermore, the low response time characteristic can also be used for high speed control of manipulation force during an assembly or microgripper holding cases.

For these reasons, we propose using a simple and effective hybrid control law, making possible the switch between the coarse and fine positioning modes. Here, hybrid control means that continous and discrete aspects are present. The discrete states are composed of the two positioning modes. Let us first design the dynamic (continous) controller of each mode.

\section{A. Coarse positioning mode}

In this sub-section, the thermomechanical part is controlled. A Proportional-Integral (PI) controller $C_{i}(s)=$ $\frac{i(s)}{\varepsilon(s)}=K_{p}^{i}\left(1+\frac{K_{i}^{i}}{s}\right)$ is proposed. Fig. 9-a gives the closed-loop scheme where $\delta_{r}$ is the reference input. The controller gains were adjusted using the Ziegler-Nichols tuning method, whose results were sufficient for our applications. We get: $K_{p}^{i}=0.004$ and $K_{i}^{i}=0.06$.
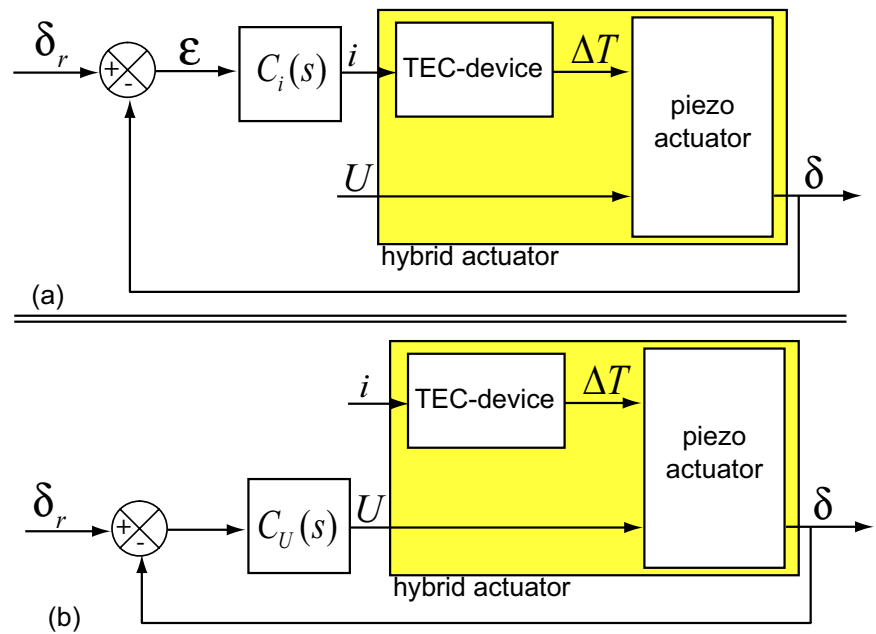

Fig. 9. (a) closed-loop scheme of the coarse positioning mode (thermomechanical part). (b) closed-loop scheme of the fine positioning mode (piezoelectric part).

\section{B. Fine positioning mode}

When the distance between the reference input $\delta_{r}$ and the output $\delta$ becomes less than a defined value $\delta_{\max }^{U}$, the fine positioning mode is activated and the piezoelectric part is controlled. The constant value $\delta_{\max }^{U}$ gives the maximum range within which the piezoelectric part works. Fig. 9-b shows the corresponding closed-loop scheme. 
A PID controller, $C_{U}(s)=K_{p}^{U}\left(1+\frac{K_{i}^{U}}{s}+K_{d}^{U} \frac{s}{\tau_{f} s+1}\right)$, was used for the fine positioning mode. The aim is to ensure the precision (by the integral action) and to damp the vibration seen in Fig. 7 (by the derivative action). Once again, a Ziegler-Nichols tuning method was efficient to obtain the expected performances. We have: $K_{p}^{U}=$ $0.06, K_{i}^{U}=500, K_{d}^{U}=0.2 \times 10^{-3}$ and the time constant $\tau_{f}$ of the filter is chosen to be $\tau_{f}>>K_{d}^{U}$.

\section{Complete control}

To bring together the control of the two previous modes in one scheme, we propose the scheme presented in Fig. 10. In the proposed scheme, the controller $\Sigma$ is defined by:

$$
\begin{aligned}
& \text { if } \quad|\varepsilon|>\delta_{\max }^{U} \quad \text { do } \\
& \varepsilon_{U}=0 \\
& \text { else } \\
& \varepsilon_{U}=\varepsilon \\
& \text { end }
\end{aligned}
$$

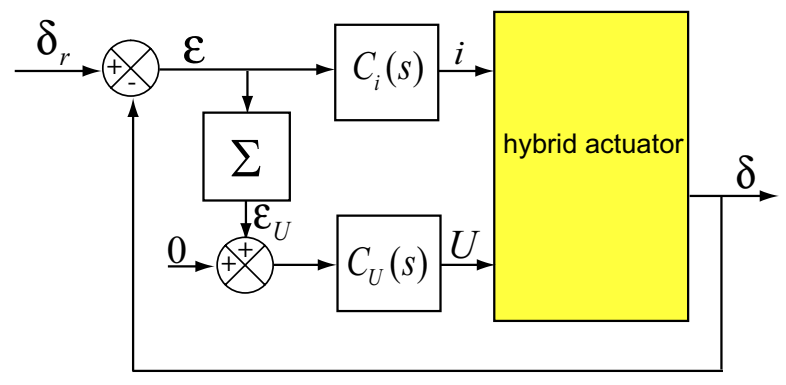

Fig. 10. Complete control scheme of the hybrid microactuator.

The controllers were implemented. Based on Fig. 8, we choose $\delta_{\max }^{U}=7 \mu \mathrm{m}$. Its choice depends on the maximum possibility of the piezoelectric actuation. A series of reference input steps $\left(\delta_{r}= \pm 100 \mu \mathrm{m}\right.$ and $\left.\delta_{r}= \pm 50 \mu \mathrm{m}\right)$ were applied at different instants. Fig. 11-a show how the output $\delta$ successfully reaches the reference. In order to see the functionning of the two modes, the current $i$ and the voltage $U$ were also recorded and plotted (Fig. 11-b and -d. Finally, Fig. 11-c shows the temperature applied by the TEC-device to the piezocantilever and measured with the thermistor. When the distance between $\delta_{r}=100 \mu \mathrm{m}$ and the output is large $\delta$ is large (for example, see for $t<10 \mathrm{~s}), i$ evoluates. From $t \approx 10 \mathrm{~s}$, the current $i$ becomes constant and the voltage $U$ starts to evoluate as $\delta$ becomes less than $\delta_{\max }^{U}=7 \mu \mathrm{m}$. Fig. 12 is a zoom of a step response for $\delta_{r}=100 \mu \mathrm{m}$. It shows more clearly the switching to the fine positioning mode.

\section{Conclusion}

The aim of this paper was the presentation of a new microactuator type based on the thermal bimorph principle and a piezoelectric cantilever, called hybrid microactuator. The main advantage is the combination
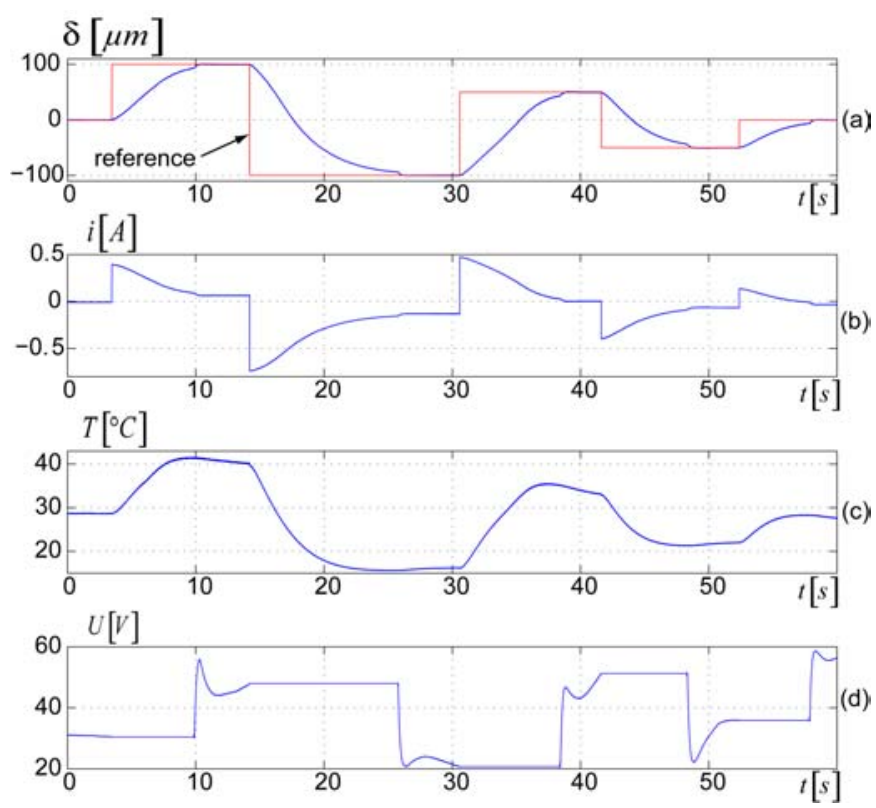

Fig. 11. Responses of the closed-loop system.

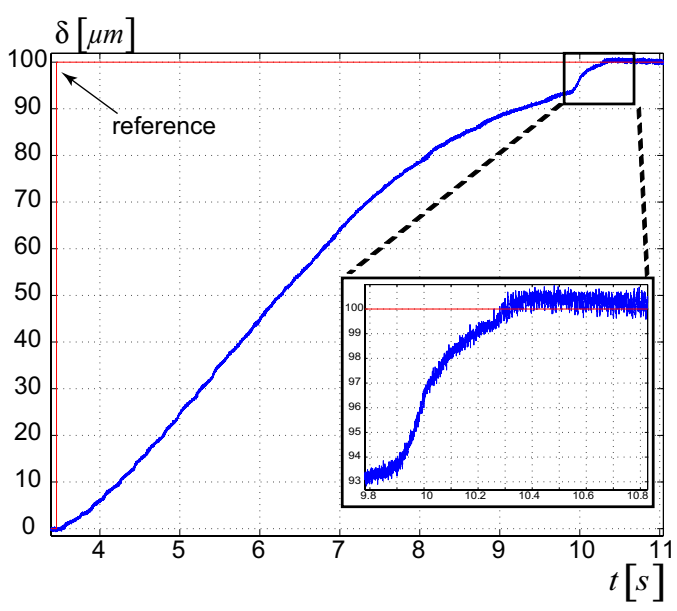

Fig. 12. Zoom of the step response of the closed-loop system.

of the large displacement obtained with the thermal actuation and the high resolution and high speed obtained with the piezoelectric actuation. To provide the thermal excitation, a Peltier (TEC) device was used. Hence, the hybrid microactuator can perform both coarse and fine positionings that are often required in micromanipulation and microassembly tasks. Roughly, it was shown that initial piezoelectric actuation range is improved by a factor of $4 \times$. The second part of the paper was dedicated to a characterization and modeling of the hybrid microactuator. In the purpose of the design of a simple and efficient controller, a linear model was proposed. Afterwards, we proposed an adapted control law, which is hybrid, to manage the coarse and the fine positioning. Finally, experimental results performed at $\pm 100 \mu m$ of displacement, show the efficiency of the proposed 
control law and foresee that such a microactuator is very interesting for tasks in the micro-world. Future works will be dedicated to the design, control and task applications of a microgripper based on the presented hybrid microactuator principle.

\section{ACKNOWLEDGMENT}

This work is supported by the EU FP7SP3-People Program under Grant No: PIEF-GA-2008-219412 (New Micro-Robotic Systems featuring Piezoelectric Adaptive MicroStructures for Sensing and Actuating, with Associated Embedded Control: MicroPAdS).

\section{REFERENCES}

[1] G. Bining, C. F. Quate and Ch. Berger, "Atomic Force Microscope", Physical Review Letters Vol.56, pp.930-933, 1986.

[2] S. Fatikow, B. Magnussen and U. Rembold, "A piezoelectric mobile robot for handling of microobjects", International Symposium on Microsystems, Intelligent Materials and Robots, Sendai 1995.

[3] A. Bergander, W. Driesen, T. Varidel, M. Meizoso and J. M. Breguet, "Mobile $\mathrm{cm} 3$-microrobots with tools for nanoscale imaging and micromanipulation" Mechatronics Robotics (MechRob 2004), pp.1041-1047, 13-15 Aachen, Germany, September 2004.

[4] M. Rakotondrabe, Y. Haddab and P. Lutz, "Development, modelling and control of a micro/nano positioning $2 \mathrm{DoF}$ stickslip device", IEEE/ASME Transactions on Mechatronics (Tmech), DOI 10.1109/TMECH.2009.2011134, 2009.

[5] D. L. Heiserman, "Piezoelectric polymer micromanipulator", United States Patent, $N^{o}$ US 4,610,475, 1986

[6] Y. Haddab, N. Chaillet and A. Bourjault, "A microgripper using smart piezoelectric actuators", IEEE/RSJ International Conference on Intelligent Robot and Systems (IROS), Takamatsu Japan, 2000

[7] J. Agnus, J. M. Breguet, N. Chaillet, O. Cois, P. de Lit, A. Ferreira, P. Melchior, C. Pellet and J. Sabatier, "A smart microrobot on chip: design, identification and modeling", Proc. IEEE/ASME International Conference on Advanced Intelligent Mechatronics (AIM), Kobe - Japan, pp.685-690 2003.

[8] D. Sun, S. Wang, J. Sakurai, S. Hata, K-B. Choi and A. Shimokohbe, "A travelling wave type of piezoelectric ultrasonic bidirectional linear microactuator", Applied Physical Express, DOI 10.1143/APEX.2.046503, 2009.

[9] M. Rakotondrabe, C. Clévy and P. Lutz, "Complete open loop control of hysteretic, creeped and oscillating piezoelectric cantilevers", IEEE Transactions on Automation Science and Engineering (TASE), in press.

[10] M. Grossard, C. Rotinat-Libersa and N. Chaillet, "Gramianbased optimal design of a dynamic stroke amplifier compliant micro-mechanism", IEEE/RSJ International Conference on Intelligent Robot and Systems (IROS), pp.4007-4012, San Diego, CA USA, October-November 2007.

[11] H-Y. Chan and W. J. Li, "A thermally actuated polymer micro robotic gripper for manipulation of biological cells", IEEE International Conference on Robotics and Automation (ICRA), pp.288-293, Taipei Taiwan, September 2003.

[12] D. O. Popa and B. H. Kang and J. T. Wen and H. E. Stephanou and G. Skidmore and A. Geisberger, "Dynamic Modeling and Input Shaping of Thermal Bimorph MEMS Actuators", IEEE International Conference on Robotics and Automation (ICRA), pp.1470-1475, Taipei Taiwan, September 2003.

[13] A. Jain, H. Qu, S. Todd and H. Xie, "A thermal bimorph micromirror with large bi-directional and vertical actuation", Elsevier Sensors and Actuators A (S\&A), pp.9-15, 2005.

[14] Micky Rakotondrabe, Cédric Clévy and Philippe Lutz, "Hinf deflection control of a unimorph piezoelectric cantilever under theraml disturbance", IEEE International Conference on Intelligent Robots and Systems (IROS), pp:1190-1197, San Diego CA USA, Oct-Nov 2007.
[15] B. Lopez-Walle, M. Gauthier and N. Chaillet, "Principle of a submerged freeze gripper for microassembly", IEEE Transactions on Robotics (TRO), Vol.24, No4, pp.897-902, 24, 2008.

[16] http://www.supercool.se/

[17] J. G. Smits and W-S. Choi, "Equations of state including the thermal domain piezoelectric and pyroelectric heterogeneous bimorph", IEEE Ultrasonics Symposium, pp.1035-1038, 1992.

[18] G. Selliger, J. Stephan and S. Lange, "Hydroadhesive gripping by using peltier effect", ASME International Mechanical Engineering Congress \& Exposition (IMECE), pp.3-8, Florida USA, November 2000.

[19] M. Rakotondrabe, Y. Haddab and P. Lutz, "Quadrilateral modelling and robust control of a nonlinear piezoelectric cantilever", IEEE Transactions on Control Systems Technolog (TCST), Vol.17, No3, pp.528-539, May 2009. 